\title{
A contribuição de Rubem Alves para o estudo da teologia na arte sequencial: anotações de um fragmento de mosaico misturadas com biografia
}

Dedicado às teólogas e aos teólogos de fronteira

Iuri Andréas Reblin ${ }^{1}$

\section{RESUMO}

O estudo apresenta duas ideias cruciais de Rubem Alves para o estudo teológico dos bens artístico-culturais da cultura pop: as estórias como invocações da vida e a teologia como atividade inerente ao ser humano. A primeira ideia remete à centralidade da narrativa no processo de constituição do mundo humano e na manutenção e contínua reinvenção deste, influindo na própria identidade do ser humano, em sua interpretação do mundo e das relações, na partilha de um universo simbólico-cultural, enfim, em sua própria biografia. A segunda ideia remete à atividade teológica enquanto faculdade inerente ao ser humano. Nessa perspectiva, Rubem Alves amplia a compreensão de teologia - usualmente entendida como estudo (acadêmico) sobre a divindade, para a dimensão humana existencial profunda da busca por sentido. Ao final, o texto reitera a importância do pensamento de Rubem Alves para

${ }_{1}$ Doutor em Teologia. Professor do Programa de Mestrado Profissional em Teologia Faculdades EST, em São Leopoldo, RS. Em 2013, recebeu o Prêmio Capes de Tese na área de Filosofia/Teologia, subcomissão Teologia, por sua pesquisa sobre histórias em quadrinhos como locus revelacionis da teologia do cotidiano. 
a teologia e seu papel particular nos estudos dos bens artístico-culturais da cultura pop.

\title{
PALAVRAS-CHAVE
}

Rubem Alves. Estudos Culturais. Teologia do Cotidiano. Arte Sequencial. Cultura Pop.

\begin{abstract}
The study presents Rubem Alves' two central ideas for the theological study of artistic cultural goods of pop culture: stories as invocation of life and theology as an inherent activity of human being. The first idea refers to the centrality of storytelling in the creation process of the human symbolic world, its maintenance and its continuous reinvention, influencing in human's identity, their interpretation of the world and the relations in it, the sharing of a symbolic cultural universe, finally, his own biography. The second idea refers to the theological activity while a faculty inherent to the human being. In this perspective, Rubem Alves expands his understanding of theology - usually understood as (academic) study on the deity, to a deeper existential human dimension of the seek for meaning. At the end, the text reiterates the importance of Rubem Alves' thought to theology and his particular role in the study of artistic cultural goods of pop culture.
\end{abstract}

\section{KEYWORDS}

Rubem Alves. Cultural Studies. Theology of Daily Life. Sequential Art. Pop Culture.

\section{Considerações iniciais: uma nota pessoal}

Já ressaltei em outro momento o quanto Rubem Alves influenciou meu jeito de pensar a teologia ${ }^{2}$. Foi justamente a partir de suas ideias que

2 REBLIN, Iuri Andréas. Rubem Alves: com as borboletas, à sombra dos ipês. In: . Outros cheiros, outros sabores... o pensamento teológico de Rubem Alves. 2. ed. São Leopoldo: Oikos, 2014, p. 246-248. 
eu pude pensar a teologia como uma arte de ser, compreender e viver em sociedade, com seu caráter político, utópico e contestador, simultaneamente, cheio de esperança, brincadeira, poesia, riso, irreverência. E repensar a teologia e seu papel para a sociedade, bem como para a gestação do futuro, foi crucial tanto para que eu me tornasse teólogo quanto para que eu permanecesse teólogo. A teologia de Rubem Alves tornou possível, para mim, perceber a nuance e as vicissitudes do pensamento teológico do dia a dia em meu objeto específico de interesse: a arte sequencial na cultura pop ${ }^{3}$. A arte sequencial e a cultura pop são características típicas da era contemporânea, adquirindo contornos nítidos na primeira metade do século 20 . E, por estar vinculada a uma dinâmica própria pós-revolução industrial, com a ascensão de uma indústria cultural, e, desse modo, às dinâmicas de mercado (produção em série, expectativa de lucro, etc.), o pensamento teológico nunca se ocupou devidamente com o tema. Isto é, a teologia enquanto ciência estava voltada a questões consideradas "mais profundas", "emergentes" e "urgentes", por vezes, alienantes da vida social e, por outras, de cunho fortemente político, de transformação social, deixando as querelas de cultura "mundana", "comercial", de lado.

O pensamento teológico de Rubem Alves possibilita pensar a teologia para além de sua "zona de conforto", pois provoca seus "co-inspiradores" a perceber a teologia nas coisas do dia a dia, questionando a coisificação de fatos sociais, alertando para os riscos da absolutização dos parâmetros sociais, religiosos, científicos e para o caráter tremendum et fascinans do mistério divino ${ }^{4}$. A teologia de Rubem Alves transcende a racionalidade e a ecclesia, isto é, os espaços convencionais, alcançando a vida humana como um todo, com sua rede complexa de relações, imbricações, tessituras e vicissitudes; torna a teologia como uma questão de fundo antropológico e existencial. Como asseverado em outro momento, no exercício de traduzir

${ }^{3}$ Cf. REBLIN, Iuri Andréas. O alienígena e o menino. Jundiaí: Paco Editorial, 2015.

${ }^{4}$ ALVES, Rubem. Ciência, coisa boa... In: MARCELLINO, Nelson Carvalho (Org.). Introdução às Ciências Sociais. 15. ed. Campinas: Papirus, 2006. p. 9-16. Como sugerido também em: ALVES, Rubem. Filosofia da Ciência: introdução ao jogo e a suas regras. 10. ed. São Paulo: Loyola, 2005a. (Leituras Filosóficas). Para maiores informações, confira: REBLIN, Iuri Andréas. Outros cheiros, outros sabores... o pensamento teológico de Rubem Alves. 2. ed. São Leopoldo: Oikos, 2014, p. 55-90. 
o pensamento do teólogo mineiro, "teologia é jogo que se joga quando a vida está em jogo"s. "A teologia é antes sapiência (sabedoria intimamente vinculada ao sentido e a busca da razão do viver e do morrer)"6. E é justamente na perspectiva de uma compreensão mais ampla e antropológica do fazer teológico que se torna possível pensá-lo na interface com os mais distintos bens artístico-culturais contemporâneos.

Diante disso, a proposta deste texto é apresentar duas ideias cruciais de Rubem Alves, na minha perspectiva, para o estudo teológico dos bens artístico-culturais da cultura pop: as estórias como invocações da vida e a teologia como atividade inerente ao ser humano. Naturalmente, a apresentação dessas duas ideias é mais ilustrativa, saudosista e biograficamente refletida diante do impacto do pensamento alvesiano nos mais diferentes contextos que deveras analítica e aprofundada, dado tanto a complexidade do próprio pensamento de Rubem Alves - que se emaranha em uma gama de concepções impossíveis de serem abordadas e referidas aqui - quanto os limites espaciais para a produção deste texto $^{7}$. Ainda assim, essa apresentação evidencia o quanto o pensamento alvesiano é vanguardista, transdisciplinar e revolucionário para se pensar o ser humano, a religião, a cultura, a sociedade, a educação e a relação entre todos esses elementos.

\section{As estórias como invocações da vida}

A narratividade ocupa um lugar central no pensamento de Rubem Alves. Ela não apenas é um argumento defendido pelo pensador como é o próprio método empregado por este. A narratividade é o meio pelo

\footnotetext{
5 REBLIN, Iuri Andréas. A não ciência de Deus a partir de Rubem Alves. In: SCHAPER, Valério Guilherme; Westhelle, Vítor; OLIVEIRA, Kathlen Luana de; GROSS, Eduardo. (Org.). Deuses e Ciências na América Latina. 1. ed. São Leopoldo: Oikos; EST, 2012a, p. 111.

6 REBLIN, 2012, p. 116.

7 Para uma análise aprofundada, sugere-se a leitura de REBLIN, 2014 e 2015 e também REBLIN, Iuri Andréas. A não ciência de Deus a partir de Rubem Alves. In: SCHAPER, Valério Guilherme; Westhelle, Vítor; OLIVEIRA, Kathlen Luana de; GROSS, Eduardo. (Org.). Deuses e Ciências na América Latina. 1. ed. São Leopoldo: Oikos; EST, 2012, p. 110-121.
} 
qual os universos simbólico-culturais são constituídos, no seio de uma sociedade, o processo educativo como um todo (não apenas formal, mas num sentido antropologicamente mais profundo) garante a continuidade da vida humana e da comunidade e é o meio pelo qual, consequentemente, a religião adquire status no mundo real, é forjada, compartilhada e se sustenta. No primeiro momento, Rubem Alves vai sugerir a ênfase na narratividade ao abordar a carência humana de uma programação biológica capaz de suprir suas necessidades rudimentares de sobrevivência, razão pela qual a faculdade da linguagem e o senso de comunidade tornam-se cruciais para a vida humana. Considerando justamente que "A linguagem é a memória coletiva da sociedade" e que "Cada pessoa que entra em contato com uma criança é um professor que incessantemente lhe descreve o mundo, até o momento em que ela é capaz de perceber o mundo tal como foi descrito", intui-se que é por meio da atividade de narrar que o mundo humano é criado, gestado, transformado e mantido. A ênfase na narratividade, no ato de contar histórias e estórias torna-se elementar no pensamento e no método de Rubem Alves tanto que ele a colocará como eixo fundamental não apenas de sua percepção acerca da constituição do mundo humano, como também de seu pensamento sobre a educação e a teologia, ao passo que ele sugerirá a redefinição da tarefa do teólogo como contador estórias:

Pensei então que o teólogo deveria, talvez, abandonar a solenidade do seu título, e reaprender-se como contador de estórias, tal como o morto silencioso sobre quem ele fala. $\mathrm{O}$ teólogo vive no mundo encantado das estórias, no mundo encantado pelas estórias. [...] $\mathrm{O}$ mundo de onde vêm os teólogos é diferente, porque ele não é simplesmente um lugar onde as pessoas tinham esse interessante hábito de falar por meio de metáforas e parábolas. Ao contrário, trata-se de um mundo que é inaugurado, sustentado e iluminado pelo próprio ato de contar e repetir as estórias. Nas estórias se tece o pensamento, se apontam horizontes, se dão nomes aos desejos.... ${ }^{10}$

\footnotetext{
8 ALVES, Rubem. O Suspiro dos Oprimidos. São Paulo: Paulus, 1999, p. 15.

9 CASTAÑEDA apud ALVES, Rubem. Variações sobre a vida e a morte ou o feitiço erótico-herético da teologia. São Paulo: Loyola, 2005c, p. 59.

${ }^{10}$ ALVES, 2005c, p. 99-100.
} 
E aqui é muito importante a distinção que Rubem Alves faz entre história e estória: ao passo que a primeira é o retrato de um dado do passado, a segunda é o retrato do presente. A primeira é a história como fato, dado, como acontecimento. A segunda é a estória como princípio, gênese, gestação, como um acontecendo. "História' é aquilo que aconteceu uma vez e não acontece nunca mais. 'Estória' é aquilo que não aconteceu nunca porque acontece sempre. A 'história' pertence ao tempo; é ciência, enquanto a 'estória' pertence à eternidade; é magia"11.

Mas quando a estória se inicia um outro mundo vem a ser: o relato é curto, contado para quem está a caminho; a linguagem é direta e poética, fazendo dançar um sem-número de sentidos possíveis. e, de forma semelhante ao chiste, ele termina numa armadilha, que desarma sobre o interlocutor, no inesperado da conclusão. E ele repentinamente descobre que a estória não fala sobre um objeto, mas é uma rede que o agarra, obrigando-o a uma palavra que seja uma confissão ou uma decisão. A estória não fala sobre algo. Não pertence ao mundo do isso. Ela fala com alguém, estabelece uma rede de relações entre as pessoas que aceitam conspirar, co-inspirar em torno do fascínio do que é dito...12

Embora a leitura do texto de Rubem Alves tenda inicialmente a subentender que ele esteja se referindo às estórias contadas entre as gerações, aos mitos, às lendas e as sagas, aos contos e aos "causos" do dia a dia, às parábolas bíblicas, a estória pode se referir, num sentido lato, a qualquer estória, como as histórias de ficção, que tanto povoam o imaginário humano e os bens culturais contemporâneos: novelas, filmes, quadrinhos. Estamos contando histórias e estórias o tempo todo e, a todo o tempo, estamos, por meio de histórias e estórias, redizendo nossa biografia, confessando nossos anseios, expressando nossos medos, revelando os horizontes que orientam nosso caminhar - Claro que a intensidade desses elementos dependerá muito da intencionalidade da narrativa e de um conjunto de relações, como no caso de filmes, novelas

\footnotetext{
11 ALVES, Rubem. O amor que acende a lua. 11. ed. Campinas: Papirus, 2005b. p. 203-204. Cf. também REBLIN, 2015, p. 82.

12 ALVES, 2005b, p. 107.
} 
e quadrinhos, do retorno financeiro, da sedução e da quantidade da audiência, de políticas empresariais, etc. De todo o modo, esses fatores não subtraem nem a importância das narrativas, nem seu potencial como locus revelacionis da teologia - E a ênfase na estória como expressão e elemento constituinte fundamental da biografia humana é enfatizada justamente quando o pensador mineiro vai afirmar que o ser humano é um palimpsesto: "Somos palimpsestos, escritura sobre escritura, esquecidas, apagadas, mas indelevelmente gravadas no tecido, prontas a ressurgir, se a encantação correta for feita. Dentro de cada corpo mora uma escritura. Estória. Mais corretamente: escrituras, estórias..."13. É por compreender as estórias, as histórias de ficção, como "invocações da vida" que olhar para as diferentes histórias que são contadas diariamente - e aqui se incluem também as histórias em arte sequencial na cultura pop - torna-se uma tarefa importante da teologia. Ao olhar para as estórias no exercício hermenêutico de compreendê-las como elementos constituintes das biografias, a teologia dá um passo adiante na busca por compreender quem é o ser humano, quais são suas crenças e como as pessoas as articulam em sua vida diária de modo a poder viver melhor ${ }^{14}$.

É principalmente por causa da relação entre teologia e narratividade de estórias que a teologia pode ser compreendida como o discurso sobre as ausências, os contornos do desejo, a fala da esperança e o suspiro do corpo oprimido. Não é a teologia tradicional, escolástica, acadêmica, mas a teologia cotidianamente anunciadora e denunciadora, para não dizer, profética. "Há certas verdades que são piores que um ultraje. Mas a imaginação voa para fazer ressuscitar palavras de amor, gestos de alegria, manifestações de bondade... Verdades podem ser nada mais que necrológios, mas as estórias são invocações da vida" ${ }^{15}$. Ou como afirmado em outro momento, "as estórias delimitam os contornos de uma grande ausência que mora em nós. Em outras palavras: elas contam um Desejo. E todo Desejo é verdadeiro"16. De todo o modo, o princípio elementar para o estudo de uma teologia do cotidiano expressa na arte sequencial e

\footnotetext{
13 ALVES, Rubem. Mares Pequenos - Mares Grandes (para começo de conversa). In: Morais, Regis de (Org.). As razões do mito. Campinas: Papirus, 1988, p. 13-21, p. 17.

${ }^{14}$ Cf. REBLIN, 2015, cap. 2.

15 ALVES, 2005c, p. 100.

${ }^{16}$ ALVES, 1988, p. 14.
} 
na cultura pop é justamente "onde quer que encontremos estas estórias/ invocações da vida, ali encontramos a teologia" ${ }^{17}$.

\section{A teologia como atividade inerente ao ser humano}

Se, por um lado, Rubem Alves se tornou fundamental em meus estudos para a compreensão da arte sequencial na cultura pop a partir da narratividade e do lugar das estórias no universo humano, por outro lado, ele o fez por meio de um olhar sob outro ponto de vista à teologia, desconstruindo a visão sedimentada de uma teologia alheia à realidade e aos problemas do mundo. Mais ainda, Rubem Alves não apenas apontou a teologia para o mundo, indicando que, na verdade, aquela pronta deste, de situações de sofrimento, como fez das pessoas em seu dia a dia os sujeitos da teologia, outrora dominada, legitimada e autorizada quase que exclusivamente por quem detém o capital simbólico sobre ela. E é a esse olhar diferenciado, heterodoxo e multifocal à teologia que tenho chamado de "a teologia do cotidiano"18, nome emprestado de um livrinho do próprio Rubem, conceito que ele não chegou a desenvolver sistematicamente, mas que esteve sempre com ele, refletido em suas crônicas despretensiosas, eróticas e heréticas, por vezes críticas, mas sempre apaixonadas sobre a própria teologia, sem dizer que era teologia. $\mathrm{E}$ essa percepção é muito interessante, pois Rubem Alves, recorrentemente afirmava que não fazia mais teologia, que havia se demitido e se distanciado desta ${ }^{19}$, o que é compreensível quando se coloca, lado a lado, a

17 ALVES, 2005c, p. 100.

18 REBLIN, 2014, p. 189-210; Cf. também REBLIN, Iuri Andréas. A teologia do cotidiano. In: BOBSIN, Oneide et al. (Orgs.). Uma Religião Chamada Brasil: estudos sobre religião e contexto brasileiro. 2. ed. São Leopoldo: Oikos, 2012b, p. 84-98.

19 "Mudei muito. Confesso que nem preciso de Deus para fazer teologia. Teólogo mesmo se benze todo, ante tal afirmação. Mas os poetas entendem. 'Saudade é o revés do parto. É arrumar o quarto para o filho que já morreu.' Quem teve filho sabe. Mas quem nunca teve... Ainda que Deus não exista, perante a sua Ausência erigirei meus altares e cantarei meus poemas. Mas sei que isto parece absurdo para aqueles que só arrumam o quarto do Filho quando sua existência está garantida (ainda que invisível) ou quando sua Vinda já se anuncia... Que vocês decidam onde está o maior amor. Minha teologia não precisa da existência de Deus. Por isto, deixou de ser teologia. 
reinvenção do sentido do termo que ele realiza e suas inúmeras crônicas em contraponto com a compreensão tradicional de teologia. A teologia sempre está lá. Como ele mesmo afirmou nas primeiras linhas de seu feitiço erótico-herético da teologia,

Escrevi este livro por não ter alternativas. Sou teólogo, lá no fundo, nos meus sonhos... Brinco com os símbolos da minha tradição cristã. Não foi escolha minha. Aconteceu. E, querendo ou não, quando estou falando com os outros ou comigo mesmo, de vez em quando um intrometido se insinua, não importando que já esteja morto faz muito tempo, e reconheço, pelo que me é segredado, que é Agostinho, ou Lutero, ou Bonhoeffer. [...] É assim que entendo teologia. Falar sobre a vida, suas coisas mais simples e mais graves, com amor, usando símbolos/memórias que uma tradição enfiou na minha carne. É por isto que não tenho alternativas ${ }^{20}$.

Neste mesmo livro no qual o pensador mineiro concede lampejos sistemáticos de sua compreensão da teologia, Rubem Alves sugere que a teologia transcende as instituições religiosas, sem se submeter ou se restringir a estas, mesmo que este seja o desejo dos líderes religiosos, intenção bem ilustrada por Pierre Bourdieu ${ }^{21}$. Para o teólogo mineiro, a teologia é sapiência, um saber vinculado à vida e as questões relacionadas ao viver e ao morrer hoje, aos símbolos e aos horizontes dos quais o ser humano se nutre para resistir e caminhar. Teologia é uma fala primeiramente abraçada pelo corpo: "O corpo não está em busca da verdade objetiva que mora com a ciência, mas da verdade gostosa e erótica que vive com a sápida-ciência, sapiência, ciência saborosa, ciência que tem a ver com viver e morrer"22. É um movimento humano de busca por um

Passou a ser poesia. Ela não prova nada. E nem quer. Somente anuncia Ausências, objetos para os quais a minha nostalgia se inclina. [...] Demito-me da teologia. Não tenho nenhuma verdade a compartilhar. Mas ponho o meu corpo na poesia. É só o que tenho a oferecer..." ALVES, Rubem. Sei que a vida vale a pena... Tempo e Presença. Rio de Janeiro, n. 224, p. 26-27, out. 1987, p. 27.

${ }^{20}$ ALVES, 2005c, p. 11.

${ }^{21}$ BOURDIEU, Pierre. A economia das trocas simbólicas. 6. ed. São Paulo: Perspectiva, 2005.

${ }^{22}$ ALVES, 2005c, p. 78. 
lugar no mundo, movimento que emerge de situações de sofrimento: "A teologia é um dizer daquilo que o corpo só pode chorar" ${ }^{23}$. E, nessa direção, a asseveração elementar de o feitiço erótico-herético da teologia que traduz a ideia central da teologia de Rubem Alves é aquela em que Rubem afirma que

[...] a teologia é uma função natural como sonhar, ouvir música, beber um bom vinho, chorar, sofrer, protestar, esperar... Talvez a teologia nada mais seja que um jeito de falar sobre tais coisas dando-lhes um nome e apenas distinguindo-se da poesia porque a teologia é sempre feita como uma prece... Não, ela não decorre do cogito da mesma forma como poemas e preces. Ela simplesmente brota e se desdobra, como manifestação de uma maneira de ser: "suspiro da criatura oprimida" - seria possível uma definição melhor? ${ }^{24}$

Quais são as implicações dessa afirmação? Há inúmeras, mas a principal para nossos propósitos aqui é a de que a teologia é um discurso humano, um discurso que parte da realidade concreta e palpável do corpo em sua relação com o meio e com o mundo a sua volta, sobre esperanças, anseios corporificados neste mesmo mundo a sua volta, traduzidos numa ordo amoris. A teologia proposta por Rubem Alves fala sobre uma transfiguração da realidade sob a ótica dos símbolos de beleza, sob a ótica do amor, sobre a transfiguração do próprio saber sob a perspectiva do amor $^{25}$. E para o estudo dos bens artístico-culturais contemporâneos da cultura pop, em especial, da arte sequencial (quadrinhos, cinema, animações), isso significa uma olhar mais atento e respeitoso a esses bens, pois, enquanto narrativas que expressam, de um jeito ou de outro, a jornada humana, estes são locus revelacionis da teologia, de uma teologia cotidiana. É sob a inspiração do pensamento alvesiano, dialogado com outros pensadores numa perspectiva interdisciplinar (tais como Pierre Bourdieu, Clifford Geertz, Michel de Certeau, Jorge Larrosa, Umberto Eco) que é possível traduzir a relação entre teologia, arte e cultura através de quadro teses ou princípios centrais:

\footnotetext{
${ }^{23}$ ALVES, 2005c, p. 55.

${ }^{24}$ ALVES, 2005c, p. 21.

25 ALVES, Rubem. Teologia. Tempo e Presença. Rio de Janeiro, n. 206, 1986, p. 32.
} 
1. Teologia, arte e cultura são facetas de nosso universo simbólico e de sentido;

2. A teologia se imiscui nos meandros da vida social cotidiana;

3. O ser humano é formado pela justaposição transitiva de histórias recebidas;

4. A tarefa da teologia é a leitura de mundo na perspectiva da experiência religiosa ${ }^{26}$.

A partir dessas teses ou princípios centrais é possível, com base no pensamento de Rubem Alves, lançar um olhar à arte sequencial, sob o viés da teologia, a fim de buscar compreender a teologia que se imiscui nos meandros da vida cotidiana e que vai acontecendo, sendo jogada, exercida enquanto a vida está em jogo. E é justamente nesse movimento, no exercício humano de se narrar a própria história como uma estória que essas mesmas estórias se tornam lugar de manifestação, apresentação e representação da experiência religiosa, expressa em argumentos teológicos, com todas as imbricações, todas as tessituras e todas as vicissitudes das quais a vida humana é feita, inventada e recriada cotidianamente. E é, na minha leitura, a partir do pensamento de Rubem Alves, com essas manifestações, essas sinuosidades fluidas (no sentido de uma teologia que sempre está se escapando por entre os dedos de uma mão que tenta segurar a água) reveladas pelo teólogo mineiro que a teologia (acadêmica) é convidada a se ocupar e a dialogar.

\section{Considerações Finais}

A teologia ainda está descobrindo o pensamento teológico de $\mathrm{Ru}-$ bem Alves e ainda está para se dar conta de sua importância para o exercício hermenêutico de interpretação do ser humano em sua vida diária, com suas ambiguidades e suas contradições, com seus anseios e seus sonhos de liberdade, sua fé e suas crenças, expressas nos mais diferentes

${ }^{26}$ REBLIN, Iuri Andréas. Teologia, arte e cultura: os caminhos da teologia do cotidiano. In: JACOBSEN, Eneida; SINNER, Rudolf von; ZWETSCH, Roberto E. (Org.). Teologia Pública: desafios sociais e culturais. São Leopoldo: Sinodal, 2012c, p. 181-200. 
bens culturais. É um porvir teológico no campo das ciências e da academia, sobretudo, pelo fato de o próprio Rubem escapar das amarras acadêmicas e relacionar a teologia com o cotidiano, com os assombros e os fascínios da vida e da morte, com o sentido da existência e, no fundo, da felicidade. O ser humano faz teologia porque busca cotidianamente se compreender no mundo, ver seus anseios e seus valores corporificados no ambiente que o rodeia, ter um lar onde possa se sentir amado e acolhido. A teologia é o discurso da esperança a despeito de e parte sempre como desejo profundo, como clamor, por um universo que faça sentido.

E o lugar da teologia? Nada mais que parte dessa sinfonia de gemidos: fala sobre Deus, que é a confissão de uma nostalgia infinita, que brota desse corpo tão bom e amigo, que pode sorrir, acariciar, plantar, tocar flauta, fazer amor, empinar papagaio, entregar-se como holocausto por aqueles a quem ama e mesmo fazer teologia. Teologia: poesia do corpo, sobre esperança e nostalgias, pronunciadas com uma prece... ${ }^{27}$

Essas duas ideias de Rubem Alves, as estórias como invocações da vida e a teologia como atividade inerente ao ser humano tornam possível driblar um tanto a hierarquia dos saberes, a soberba de teólogos (homens) enquanto porta-vozes do divino, e lançar um olhar ao cotidiano, promovendo um diálogo equilibrado com outros saberes humanos que realizam o exercício de interpretar a realidade e o ser humano para possibilitar uma vida melhor. A leitura de mundo, o olhar ao cotidiano visa compreensão e, a partir de anseios partilhados, uma transformação social. Afinal, como afirmou Rubem Alves "o que a gente deseja não é viver apenas na nostalgia e na beleza do símbolo, mas a gente quer que esses símbolos de beleza se transformem numa realidade para o mundo em que vivemos"28. E é para isso que fazemos teologia.

27 ALVES, 2005c, p. 41.

${ }^{28}$ RUBEM Alves: os símbolos. Direção e produção de Armando Celia Jr. e Celso Pavarin Jr. Coordenação de Marina Escolar. Campinas: Vídeo Arqui/ABEC, [s.d]. 1 videocassete (51 $\mathrm{min})$, VHS, son., color. $\sim 48$ '. 


\section{Referências Bibliográficas}

ALVES, Rubem. Ciência, coisa boa... In: MARCELLINO, Nelson Carvalho (Org.). Introdução às Ciências Sociais. 15. ed. Campinas: Papirus, 2006, p. 9-16.

ALVES, Rubem. Filosofia da Ciência: introdução ao jogo e a suas regras. 10. ed. São Paulo: Loyola, 2005a. (Leituras Filosóficas)

ALVES, Rubem. Mares Pequenos - Mares Grandes (para começo de conversa). In: Morais, Regis de (Org.). As razões do mito. Campinas: Papirus, 1988, p. 13-21.

ALVES, Rubem. O amor que acende a lua. 11. ed. Campinas: Papirus, $2005 \mathrm{~b}$.

ALVES, Rubem. O Suspiro dos Oprimidos. São Paulo: Paulus, 1999.

ALVES, Rubem. Sei que a vida vale a pena... Tempo e Presença. Rio de Janeiro, n. 224, p. 26-27, out. 1987, p. 27.

ALVES, Rubem. Teologia. Tempo e Presença. Rio de Janeiro, n. 206, 1986, p. 32.

ALVES, Rubem. Variações sobre a vida e a morte ou o feitiço erótico -herético da teologia. São Paulo: Loyola, 2005c.

BOURDIEU, Pierre. A economia das trocas simbólicas. $6^{\mathrm{a}}$ ed. São Paulo: Perspectiva, 2005.

REBLIN, Iuri Andréas. A não ciência de Deus a partir de Rubem Alves. In: SCHAPER, Valério Guilherme; Westhelle, Vítor; OLIVEIRA, Kathlen Luana de; GROSS, Eduardo. (Org.). Deuses e Ciências na América Latina. 1. ed. São Leopoldo: Oikos; EST, 2012a, p. 110-121.

REBLIN, Iuri Andréas. A teologia do cotidiano. In: BOBSIN, Oneide et al. (Orgs.). Uma Religião Chamada Brasil: estudos sobre religião e contexto brasileiro. 2. ed. São Leopoldo: Oikos, 2012b, p. 84-98.

REBLIN, Iuri Andréas. Outros cheiros, outros sabores... o pensamento teológico de Rubem Alves. 2. ed. São Leopoldo: Oikos, 2014. Disponível em: <http://www.est.edu.br/downloads/pdfs/biblioteca/livrosdigitais/REBLIN-Outros_cheiros.pdf $>$. Acesso em: 28 fev. 2015.

REBLIN, Iuri Andréas. Rubem Alves: com as borboletas, à sombra dos ipês. In: . Outros cheiros, outros sabores... o pensamento teológico de Rubem Alves. 2. ed. São Leopoldo: Oikos, 2014, p. 246-248. Disponível em: <http://www.est.edu.br/downloads/pdfs/biblioteca/livros-digitais/REBLIN-Outros_cheiros.pdf $>$. Acesso em: 28 fev. 2015. 
REBLIN, Iuri Andréas. Teologia, arte e cultura: os caminhos da teologia do cotidiano. In: JACOBSEN, Eneida; SINNER, Rudolf von; ZWETSCH, Roberto E. (Org.). Teologia Pública: desafios sociais e culturais. São Leopoldo: Sinodal, 2012c, p. 181-200.

RUBEM Alves: os símbolos. Direção e produção de Armando Celia Jr. e Celso Pavarin Jr. Coordenação de Marina Escolar. Campinas: Vídeo Arqui/ABEC, [s.d]. 1 videocassete (51 min), VHS, son., color.

Submetido em: 14/05/2014 Aceito em: 03/06/2015 